\title{
Alfabetização de Jovens e Adultos
}

\author{
Educación de Jóvenes y Adultos \\ Literacy of Young People and Adults
}

\author{
Marysol Fernandez Garcia Janke ${ }^{1}$ \\ Everton Fêrrêr de Oliveira ${ }^{2}$ \\ Jeane Andreia Dorneles ${ }^{3}$ \\ Helena Beatriz Costa de Oliveira ${ }^{4}$
}

\begin{abstract}
Resumo
Nosso trabalho está contextualizado pela iniciação à docência do Programa Institucional de Bolsas de Iniciação à Docência da UNIPAMPA, Subprojeto Pedagogia, área temática Modalidade de Ensino: Educação Especial e Educação de Jovens e Adultos (EJA) financiado pela CAPES em articulação com Programa de Desenvolvimento Acadêmico (PDA)a partir do projeto de extensão intitulado Manutenção e desenvolvimento de comunidade de aprendizagem virtual multimídia em rede social na Educação de Jovens e Adultos (EJA do Brasil) - Portal dos Fóruns de Educação de Jovens e Adultos. Os objetivos residem na promoção, visibilidade e projeção das modalidades de ensino, tendo em vista que nossa ação vem subsidiando políticas públicas locais como o Plano Municipal de Educação (PME) que contou com os dados de pesquisas e ações do PIBID para sua elaboração no ano de 2014. Neste recorte utilizamos o Método Paulo Freire e a perspectiva de Educação Crítica e Democrática na identificação do contexto significativo do universo vocabular com adultos analfabetos da Comunidade do entorno da universidade. É no trabalho de alfabetização que temos a formação inicial em evidência, pois as leituras, discussões, reuniões de planejamento sobre a prática de Alfabetização na EJA vai permitindo ampliar nossa compreensão sobre a mesma. Até o momento podemos apontar que articulação entre ensino e extensão tem possibilitado a criação de dispositivos pedagógicos inovadores, entrelaçados e significativos, pois a presença de sujeitos da comunidade no meio universitário permite a problematização das desigualdades sociais e do papel da universidade para mudar estes cenários de desigualdade e injustiça social.
\end{abstract}

Palavras-Chave: Iniciação à Docência; Extensão; Educação de Jovens e Adultos.

\section{Resumen}

Nuestro trabajo se enmarca en la preparación para la docencia del Programa Institucional de Becas de Iniciación a la Docencia (PIBID) de la UNIPAMPA, Subproyecto Pedagogía, área temática Modalidad de Enseñanza: Educación Especial y Educación de Jóvenes y Adultos (EJA), financiado por la CAPES en colaboración con el Programa de Desarrollo Académico (PDA), a partir del proyecto de extensión denominado Manutención y desarrollo de colectividad de aprendizaje virtual multimedia en red social para la Educación de

\footnotetext{
${ }^{1}$ Formanda em Licenciatura em Pedagogia; Universidade Federal do Pampa; Jaguarão, Rio Grande do Sul, Brasil; mfjanke@gmail.com. Trabalho apresentado no III Encontro Humanístico Multidisciplinar e II Congresso Latino-Americano de Estudos Humanísticos Multidisciplinares -, Jaguarão/ RS, Brasil, 2017.

${ }^{2}$ Prof. Adjunto e Coordenador do Curso de Licenciatura em Pedagogia; Universidade Federal do Pampa (UNIPAMPA); Jaguarão, Rio Grande do Sul, Brasil; evertonoliveira@unipampa.edu.br. Trabalho apresentado no III Encontro Humanístico Multidisciplinar e II Congresso Latino-Americano de Estudos Humanísticos Multidisciplinares, Jaguarão/ RS, Brasil, 2017.

${ }^{3}$ Formanda em Licenciatura em Pedagogia; Universidade Federal do Pampa; Jaguarão, Rio Grande do Sul, Brasil; jeaneandreiadorneles1@gmail.com. Trabalho apresentado no III Encontro Humanístico Multidisciplinar e II Congresso Latino-Americano de Estudos Humanísticos Multidisciplinares, Jaguarão/ RS, Brasil, 2017.

${ }^{4}$ Formanda em Bacharel em Produção e Política Cultural; Universidade Federal do Pampa; Jaguarão, Rio Grande do Sul, Brasil; hhoxum@gmail.com. Trabalho apresentado no III Encontro Humanístico Multidisciplinar e II Congresso Latino-Americano de Estudos Humanísticos Multidisciplinares, Jaguarão/ RS, Brasil, 2017.
} 
Jóvenes y Adultos (EJA de Brasil) - Portal de los Foros de Educación de los Jóvenes y Adultos. Los objetivos radican en la promoción, visibilidad y proyección de las modalidades de enseñanza, teniendo en cuenta que nuestra acción viene subsidiando políticas públicas locales, como el Plan Municipal de Educación (PME) que dispuso de los datos y acciones del PIBID para su elaboración, el año 2014. En nuestro enfoque utilizamos el Método Paulo Freire y la perspectiva de Educación Crítica y Democrática para la identificación del contexto significativo del universo lexicológico entre adultos analfabetos en la Comunidad que circunda a la Universidad. Es mediante el trabajo de alfabetización como se evidencia su formación inicial, pues las lecturas, discusiones, reuniones de planificación sobre la práctica de Alfabetización en la EJA, nos permite ampliar nuestra comprensión al respecto. Hasta ahora podemos destacar que la coordinación entre enseñanza y extensión ha posibilitado que se creen dispositivos pedagógicos innovadores, interrelacionados y significativos, pues la presencia de individuos de la comunidad en el ámbito universitario propicia la discusión de las desigualdades sociales y el rol de la universidad para cambiar tales contingencias de desigualdad e injusticia social.

Palabras claves: Iniciación a la Docencia; Extensión; Educación de Jóvenes y Adultos.

\begin{abstract}
Our work is part of the preparation for teaching the Institutional Scholarship Program of Initiation to Teaching (PIBID) of the UNIPAMPA, Subproject Pedagogy, thematic area Modality of Teaching: Special Education and Education of Young People and Adults (EJA), financed by CAPES in collaboration with the Academic Development Program (PDA), based on the extension project called Managing and developing a collective of multimedia virtual learning in a social network for the Education of Young People and Adults (EJA of Brazil) Portal of the Forums of Education for Young People and Adults. The objectives lie in the promotion, visibility and projection of teaching methods, taking into account that our action is subsidizing local public policies, such as the Municipal Education Plan (PME), which has data and actions of the PIBID for its elaboration, the year 2014 .In our approach, we use the Paulo Freire Method and the perspective of Critical and Democratic Education for the identification of the significant context of the lexicological universe among illiterate adults in the Community that surrounds the University. It is through literacy work as evidenced by their initial formation, since the readings, discussions, planning meetings on the practice of Literacy in the EJA, allow us to broaden our understanding in this regard. Up to now, we can emphasize that the coordination between teaching and extension has made it possible to create innovative, interrelated and significant pedagogical devices, since the presence of individuals from the community in the university environment encourages the discussion of social inequalities and the role of the university for change such contingencies of inequality and social injustice.
\end{abstract}

Keywords: Introduction to Teaching; Extension; Education of Youth and Adults.

\title{
1. Introdução
}

Iniciamos nosso trabalho com o processo de alfabetização no projeto de extensão de Educação de Jovens e Adultos (EJA) na Universidade Federal do Pampa (UNIPAMPA), campus Jaguarão. Nosso trabalho se desenvolve a partir do projeto de extensão intitulado Manutenção e desenvolvimento de comunidade de aprendizagem virtual multimídia em rede social na Educação de Jovens e Adultos (EJA do Brasil) - Portal dos Fóruns de Educação de Jovens e Adultos, vinculado ao Programa de Desenvolvimento Acadêmico (PDA) com interface no Programa Institucional de Iniciação à Docência (PIBID) na Modalidade de Ensino: Educação Especial - EJA. O referido projeto potencializa a formação de educadores quando articula o saber do curso de Pedagogia através do componente curricular JP0024- Os sujeitos e a prática pedagógica na EJA como uma prática de pesquisa e estudo sobre o movimento social em prol da EJA, em ações e práticas docentes compartilhadas com a 
implantação de uma classe de alfabetização e letramento de adultos analfabetos de uma comunidade próxima ao campus universitário e possibilitando a inclusão digital desses educandos.

Nossa ação-reflexão-ação tem como norte o Plano Municipal de Educação (PME) criado em 2014 que dá as principais estratégias para a Educação de Jovens e Adultos (EJA), a metodologia freireana, que auxiliará no trabalho dos profissionais da EJA, como também aos que estão na Iniciação à Docência numa perspectiva de Educação Popular.

Partindo da perspectiva da Educação Popular, construímos nosso caminho no viés de alfabetização dos alfabetizandos da EJA numa perspectiva crítica e democrática como ressalta (LEITE, E. C; HAMES, G. S; SILVA, I. S; COSTA, T. C e MAURÍCIO, W. P. D., 2016, p. 122):

O conceito de democracia surge no meio educacional de maneira gradativa. De acordo com Saviani (1944), "a democracia supõe condições de igualdade entre os diferentes agentes sociais" (SAVIANI, 1944, p. 86). Assim, compartilhando da visão do autor, trouxemos essa temática para trabalhar com os sujeitos da EJA, a fim de conscientizá-los de que são cidadãos com direitos e deveres, e que devem ser devidamente respeitados.

Ou seja, nessa temática da Educação Popular atrelada aos aspectos democráticos e críticos que procuramos justamente como apontam os autores, proporcionar uma reflexão com os educandos da EJA de que eles são portadores de direitos que por muito tempo foram cerceados como é o direito à educação. Outro ponto importante dentro do aspecto democrático é o diálogo, que pressupõem uma troca entre os pares: Professor - professores em formação, Professor - educando e Educando - educando.

Referente aos educandos que são vinculados ao Projeto EJA, são moradores de uma comunidade periférica próxima ao campus da UNIPAMPA/Jaguarão, na qual, os educandos vieram remanejados do Programa Brasil Alfabetizado.

\section{Metodologia}

Optamos por trabalhar com Freire, pois este, atenta para um processo de aprendizagem mais abrangente e plural, respeitando a diversidade cultural, comportamental e de classe (ou seja, classes mais abastadas e classe menos favorecidas), visa defender a aprendizagem baseada na interação com o ambiente, os objetos do cotidiano. Sendo que o método Paulo Freire, nos ajuda a organizar os materiais de aula: como Planos de Aula, e planejar atividades correspondentes à EJA (jogos, alfabeto móvel, cartilhas de alfabetização) e cyberspace que possibilita aos educandos da EJA a se inserirem no mundo digital. 
Por meio da ação-reflexão-ação nos é possível reconhecer a problemática, quais as dificuldades e desafios enfrentados pelos adultos que estudam no projeto e aprendermos nas/com as práticas educativas num processo de trocas da educação compartilhada.

Para tanto contribui o educador Freire:

[...] a prática docente crítica, implicante do pensar certo, envolve o movimento dinâmico, dialético, entre o fazer e o pensar sobre o fazer. [...] O que se precisa é possibilitar, que, voltando-se sobre si mesma, através da reflexão sobre a prática, a curiosidade ingênua, percebendo-se como tal, se vá tornando crítica. [...]A prática docente crítica, implicante do pensar certo, envolve o movimento dinâmico, dialético, entre o fazer e o pensar sobre o fazer. (FREIRE, 2002 p. 42-43)

Primeiramente passamos ao que o nosso orientador denominou de alinhamento das expectativas e a testagem dos conhecimentos dos educandos para identificar os seus anseios frente ao que gostariam de aprender e quais conhecimentos já haviam adquirido.

Quanto ao saber construído socialmente por estes educandos e trazido até nós professores/as em formação contribui Becker:

O educador, na educação problematizadora, refaz e reconstrói constantemente, o seu conhecimento na capacidade de conhecimento de seus educandos; estes passam a investigar criticamente a realidade em diálogo com o educador que, por este mesmo processo dialógico, torna-se também um investigador crítico. (In Hoffmann 2009, p.46).

Nesse primeiro encontro entre educandos- educadores universitários e educandos oriundos da comunidade (alfabetizandos), acertou-se que faríamos uma testagem dos seus conhecimentos enquanto a escrita, os quais seriam de suma importância para ambos (para nós sabermos se eles conheciam as letras, sílabas, palavras).

$\mathrm{Na}$ testagem, foram empregadas quatro palavras e uma frase. As palavras compostas por: uma dissílaba, uma trissílaba, uma polissílaba, uma monossílaba. Logo a frase onde empregamos a palavra polissílaba.

As quatro palavras empregadas nessa testagem foram: vila, cidade, comunidade e chão. Após, a frase composta com a palavra polissílaba ficou assim: A comunidade é bonita.

Como ressalta Brandão (1982), seguindo o educador Paulo Freire por meio de um processo de troca entre educadores e educandos fomos apropriando-nos das palavras geradoras que faziam parte do cotidiano dos moradores da comunidade num momento mútuo de descoberta: para nós sobre o que eles pensavam e para eles de como os pensamentos se transformavam em escrita. 
Para que essa troca de saberes acontecesse foi preciso reconhecer que "o espaço do educador democrático, que aprende a falar escutando, é cortado pelo silêncio intermitente de quem, falando, cala para escutar a quem, silencioso, e não silenciado, fala.” (FREIRE, P. 1996-2002). Por isso ressalvamos a importância da motivação do educando a falar, a se colocar como ser pensante, a expressar sua fala, a reconhecer o seu lugar na comunidade, seu lugar na sociedade, seu lugar no mundo e que tudo isso além de dito pode ser escrito, desenvolvendo sua capacidade de compreensão de um direito: a liberdade de expressão, a liberdade de aprender, ensinar.

Nesse processo de ensinar-aprender, no preparo para o exercício da cidadania e para uma melhor qualificação para o mercado de trabalho (inquietações de alguns educandos) buscamos subsídios também na Lei de Diretrizes e Bases da Educação Nacional no 9.394/96 que traz quanto a Educação de Jovens e Adultos:

Artigo 37 - A Educação de Jovens e Adultos será destinada àqueles que não tiveram acesso ou continuidade de estudos no ensino fundamental e médio na idade própria.

$\S 1^{\circ}$. Os sistemas de ensino assegurarão gratuitamente aos jovens e aos adultos, que não puderam efetuar os estudos na idade regular, oportunidades educacionais apropriadas, consideradas as características do alunado, seus interesses, condições de vida e trabalho, mediante cursos e exames.

$\S 2^{\circ}$. O Poder Público viabilizará e estimulará o acesso e a permanência do trabalhador na escola, mediante ações integradas e complementares entre si.

Assim, nosso propósito de educador de jovens e adultos numa perspectiva democrática é fazer o resgate desses sujeitos que se encontram fora de uma sala de aula, fora da escola por diversos motivos, sejam estes econômicos, sociais, psicológicos; procuramos primeiramente recuperar sua autoestima e leva-los novamente a frequentar a escola, expandir seus conhecimentos, continuar os seus estudos e propiciar uma melhora em suas vidas e condições de trabalho.

\section{Resultados e Discussões}

Seguindo o Método Paulo Freire “(...) A descoberta coletiva da vida através da fala, do mundo através da palavra não deve servir apenas para que os educadores obtenham um primeiro conjunto de material de alfabetização palavras, frases, dados, desenhos, fotos. Devem servir para criar um momento comum de descoberta”. (BRANDÃO, 1982, p.14).

Este momento de descoberta dará subsídios para compreender como se aprende e se ensina num processo de acertos e de erros que serão sanados num próximo momento após reflexão da prática educativa. Quanto ao ensinar-aprender (CAGLIARI, 1999, p.36-37) traz: 
Ensinar é um ato coletivo: pode-se ensinar a um grande número de pessoas presentes numa sala ou numa conferência, etc. Quem ensina procura transmitir informações que julga relevantes, organizadas do modo que lhes parece mais razoável, para que seus ouvintes aprendam algo que deseja transmitir. Aprender é um ato individual: cada um aprende segundo seu próprio metabolismo intelectual. A aprendizagem não se processa paralelamente ao ensino. O que é importante para quem ensina, pode não parecer tão importante para quem aprende. A ordem da aprendizagem é criada pelo indivíduo, de acordo com sua história de vida e, raramente, acompanha passo a passo a ordem do ensino. (CAGLIARI, 1999, p.3637).

Para tanto esse processo de ensino-aprendizagem para nós que estamos em formação só é possível mediante a reflexão-ação sobre as nossas práticas educativas pautadas com responsabilidade. Assim colabora o educador Freire:

[...] não há ensaio histórico sem responsabilidade. Quer dizer, fazem parte da natureza da experiência histórica o cumprimento de deveres e a luta pela conquista de direitos. Daí que a educação popular, democrática, tal qual a vemos hoje e ontem e anunciamos, rejeitando as dicotomias distorcivas, persiga a compreensão dos fatos e da realidade na complexidade de suas relações. A formação para a qual uma educação assim crítica aponta implica necessariamente a informação. (FREIRE, 2015, p.180).

Por meio da reflexão sobre as práticas educativas (sobre a informação) o educando vai se tornando sujeito do seu ato de conhecimento. Informação que se transforma em formação. Por isso que a prática educativa pautada na reflexão crítica dos fatos, da sociedade, do mundo contribua para a formação cidadã.

E ainda complementando quanto a educação para a cidadania Freire diz:

O educador progressista precisa estar convencido como de suas conseqüências é o de ser o seu trabalho uma especificidade humana. Já vimos que a condição humana fundante da educação é precisamente a inconclusão de nosso ser histórico de que nos tornamos conscientes. Nada que diga respeito a ser humano, à possibilidade de seu aperfeiçoamento físico e moral, de sua inteligência sendo produzida e desafiada, os obstáculos a seu crescimento, o que possa fazer em favor da boniteza do mundo como de seu enfeamento, a dominação a que esteja sujeito, a liberdade por que deve lutar, nada que diga respeito aos homens e às mulheres pode passar despercebido pelo educando progressista. Não importa com que faixa etária trabalhe o educador ou a educadora. O nosso é um trabalho realizado com gente, miúda, jovem ou adulta, mas gente em permanente processo de busca. (FREIRE. Pedagogia da autonomia: saberes necessários à prática educativa. 1996. - (Coleção Leitura).

O fato desses adultos voltarem a estudar, a lutarem por uma conquista que lhes foi negada na tenra idade demonstra a força de vontade de vencer os obstáculos da vida e que ainda sonham em crescer em seus conhecimentos, viver com dignidade, de acordo as suas vontades, num mundo que dê oportunidade para todos poder alcançar os seus sonhos de uma vida melhor. 


\section{Conclusões}

Ao longo do Projeto, que por ventura ainda está em andamento, fizemos observações e reflexões que nos foram pertinentes e que também, nos possibilitaram e nos possibilita através do Método Paulo Freire de como atuar na sala de EJA, escolher quais ferramentas melhor trabalhar dentro da EJA, como podemos nos inserir na realidade dos educandos e percebemos até este ponto do Projeto (2016/2) que duas aulas por semana não são suficientes para suprir as aulas da EJA.

Para nós nesta pesquisa participante de uma educação compartilhada (ensinopesquisa) fica a constatação de que trabalhar com o público da EJA não é toma-los como objeto de estudo e sim fazer uma investigação do seu pensar em conjunto com eles para chegar ao conhecimento. E quando desse ato se chega ao conhecimento mais se quer saber e é organizando, sistematizando esses saberes que se adquire então o conhecimento que será significativo. Pensar na educação das práticas educativas na EJA é pensar que se irá trabalhar sempre na diversidade; diversidade de sujeitos sejam estes adultos, adolescentes, jovens ou idosos, homens e mulheres oriundos de classe baixa pois por sua falta de alfabetização geralmente se encontram desempenhando trabalhos na informalidade, em insalubridade, mal pagos, seja no campo ou na cidade; trabalhos que a maioria do povo não quer desempenhar. Chegam à sala de aula cansados mas com alegria de ali estarem sendo reconhecidos como seres pensantes que podem sim aprender-ensinar; porque eles e elas na sua maioria já são pais e avós e querem compartilhar o saber com essa nova geração, não querem ser descartados como algo já em desuso, pois, ainda são força de trabalho da nossa nação e necessitam ser reconhecidos e para tanto usufruir do seu direito a educação que é garantido pela Constituição Federal de 1988 e pela LDB.

O PIBID contribuiu através deste projeto, para aperfeiçoar a formação docente (teórico-metodológica) através da ação-reflexão-ação da prática de ensino podendo reelaborar a sua prática futura. Contribuiu para a reflexão permanente sobre os problemas enfrentados na prática cotidiana com os adultos, a problematização das desigualdades sociais e o papel da universidade para mudar estes cenários de desigualdade sociais e de injustiça social o que faz necessária a criação de novas políticas públicas para a EJA.

\section{Referências}

BRANDÃO, Carlos Rodrigues; ANDRADE, José Eliézer de. O que é método Paulo Freire. Editora Brasiliense, 1982. 
BRASIL. Lei de Diretrizes e Bases da Educação Nacional: Lei no 9.394 de 20 de dezembro de 1996... - Brasília: Senado Federal Subsecretaria de Edições técnicas, 2002.

BRASIL. (1988). Constituição da República Federativa do Brasil: texto cnstitucional promulgado em 5 de outubro de 1988. Brasília. Disponível em:

http://www.planalto.gov.br/ccivil_03/constituicao/constituicao.htm.

CAGLIARI, Luiz Carlos. Alfabetizando sem o bá-bé-bi-bó-bú. Pensamento e ação no Magistério. São Paulo: Scipione, 1998.

FREIRE, Paulo. Pedagogia da Autonomia: Saberes Necessários à Prática Educativa. Ano da Publicação Original: 1996 Ano da Digitalização: 2002.

Cartas a Cristina: reflexões sobre minha vida e minha práxis/ Organização e notas Ana Maria Araújo Freire. - São Paulo: Paz e Terra, 2015.

HOFFMANN, Jussara. Avaliação mediadora: uma prática em construção da pré-escola à universidadel Jussara Maria Lerch Hoffmann - Porto Alegre, 2009 (Ed. Atual ortog.) 160p.

LEITE, E. C; HAMES, G. S.; SILVA, I. S.; COSTA, T. C da e MAURÍCIO, W. P. D. in: Alfabetizando Jovens e Adultos numa perspectiva Crítica e Democrática. Revista GepesvidaUniplac - v. 2, n. 1, 2016.

PREFEITURA MUNICIPAL DE JAGUARÃO-RS: Secretaria Municipal de Educação e Desporto de Jaguarão. Conselho Municipal de Educação de Jaguarão. Plano Municipal de Educação. Jaguarão 2014- 2024 p.01-71.

Lei N. ${ }^{\circ}$ 6.151, de 25 de junho de 2015. Disponível em:

http://www.jaguarao.rs.gov.br/wp-content/uploads/2015/03/LEI-N\%C2\%BA-6.151-aprova-oPME.pdf Acesso em 21 de dezembro de 2017. 